\title{
Dimerisation of HIV-2 genomic RNA is linked to efficient RNA packaging, normal particle maturation and viral infectivity Anne L'Hernault ${ }^{1}$, Jane S Greatorex ${ }^{1}$, R Anthony Crowther ${ }^{2}$ and Andrew ML Lever*1
}

\author{
Address: ${ }^{1}$ Department of Medicine, University of Cambridge, Addenbrooke's Hospital, Cambridge CB2 2QQ, UK and ${ }^{2} \mathrm{MRC}$ Laboratory of \\ Molecular Biology, Cambridge CB2 0QH, UK \\ Email: Anne L'Hernault - al418@mole.bio.cam.ac.uk; Jane S Greatorex - jg10018@mole.bio.cam.ac.uk; R Anthony Crowther - rac1@mrc- \\ lmb.cam.ac.uk; Andrew ML Lever* - amll1@mole.bio.cam.ac.uk \\ * Corresponding author
}

Published: 13 December 2007

Retrovirology 2007, 4:90 doi:10.1 186/1742-4690-4-90

This article is available from: http://www.retrovirology.com/content/4///90

(C) 2007 L'Hernault et al; licensee BioMed Central Ltd.

This is an Open Access article distributed under the terms of the Creative Commons Attribution License (http://creativecommons.org/licenses/by/2.0), which permits unrestricted use, distribution, and reproduction in any medium, provided the original work is properly cited.
Received: 2 December 2007

Accepted: 13 December 2007

\begin{abstract}
Background: Retroviruses selectively encapsidate two copies of their genomic RNA, the Gag protein binding a specific RNA motif in the 5' UTR of the genome. In human immunodeficiency virus type 2 (HIV-2), the principal packaging signal (Psi) is upstream of the major splice donor and hence is present on all the viral RNA species. Cotranslational capture of the full length genome ensures specificity. HIV-2 RNA dimerisation is thought to occur at the dimer initiation site (DIS) located in stem-loop I (SL-I), downstream of the main packaging determinant. However, the HIV-2 packaging signal also contains a palindromic sequence (pal) involved in dimerisation. In this study, we analysed the role of the HIV-2 packaging signal in genomic RNA dimerisation in vivo and its implication in viral replication.
\end{abstract}

Results: Using a series of deletion and substitution mutants in SL-I and the Psi region, we show that in fully infectious HIV-2, genomic RNA dimerisation is mediated by the palindrome pal. Mutation of the DIS had no effect on dimerisation or viral infectivity, while mutations in the packaging signal severely reduce both processes as well as RNA encapsidation. Electron micrographs of the Psi-deleted virions revealed a significant reduction in the proportion of mature particles and an increase in that of particles containing multiple cores.

Conclusion: In addition to its role in RNA encapsidation, the HIV-2 packaging signal contains a palindromic sequence that is critical for genomic RNA dimerisation. Encapsidation of a dimeric genome seems required for the production of infectious mature particles, and provides a promising therapeutic target.

\section{Background}

Retroviruses encapsidate two copies of the positive sense single-stranded genomic RNA. Encapsidation is very specific, as the virus has to select and package the full length genomic RNA over the vast excess of cellular and subge- nomic RNA species. In human immunodeficiency virus type 1 (HIV-1), this mechanism is well understood. An RNA motif, downstream of the viral splice donor and upstream of the Gag start codon, interacts with the Gag 
structural protein and ensures specificity of encapsidation for full length rather than spliced RNAs [1-6].

In the case of HIV-2, the process is less well understood as the main packaging determinant (Psi or $\Psi$ ) appears to be located upstream of the major splice donor [7]. In a study to further map the HIV-2 encapsidation signal, a 28 nucleotides (nt) sequence upstream of the splice donor was identified as being required for HIV-2 RNA packaging [8]. To specifically encapsidate the unspliced genomic RNA, HIV-2 has been demonstrated to package its genome in a cis rather than a trans manner [9]. The structural Gag protein is translated from the full length RNA and encapsidates the RNA from the same pool from which it was translated $[8,9]$.

The cis mechanism ensures that only the full length RNA is packaged and provides the specificity. Nonetheless, the requirement for specific sequences implies that an RNA structure is involved in the process. For example, several in vitro studies have shown that long-range interactions can regulate RNA encapsidation and dimerisation, both in HIV-1 and HIV-2 [10-13]. Furthermore, a recent study of the HIV-2 5' leader region revealed that an extended stemloop 1 (SL-1) structure was required for efficient genome encapsidation and viral replication [14].

Dimerisation of retroviral genomes is thought to be linked to the encapsidation process, with elements for both often overlapping $[11,15-19]$. The HIV-2 leader has been extensively studied and a palindromic sequence within the encapsidation signal has been identified and shown to be important for the regulation of the dimerisation process in vitro $[11,20]$. In addition, several in vitro studies proposed that a palindrome located in the loop of SL-1 could act as the dimer initiation site (DIS) [21,22], similarly to what has been shown in HIV-1 $[23,24]$. To date, the dimeric nature of wild type HIV-2 RNA in cells has yet not been confirmed.

In this study, we analysed a series of SL-1 and Psi mutant viruses, including the $28 \mathrm{nt}$ deletion containing virus mentioned above. Interestingly, viruses deficient for dimerisation in vivo were also defective for encapsidation, replication and infectivity. The latter suggests a potential maturation defect and electron microscopy (EM) was performed on virions to determine whether or not this process was affected.

We present here the results of these in vivo studies and propose that a previously identified motif, the DIS palindrome, is not required for efficient dimerisation of the HIV-2 RNA in the virus. Our data suggest that genomic RNA dimerisation is mediated by a sequence located within the Psi region and that dimerisation may indeed be closely linked to viral packaging. Importantly, dimerisation defective viruses are deficient in virion maturation and infectivity, potentially offering new targets for inhibiting replication of HIV-2.

\section{Results \\ Mutation of the HIV-2 packaging signal and DIS}

We previously described the DM deletion mutant (Fig. 1A) of HIV-2 which shows a major packaging defect [8]. Recently, the formation of a stem, named stem $B$ and located at the base of SL-1 (Fig. 1B), was shown to be required for efficient genome encapsidation and viral replication [14]. The sequence involved in the formation of stem B is part of a $10 \mathrm{nt}$ palindrome (pal), located within the packaging signal Psi $(\Psi)$, and which has been suggested to play a role in RNA dimerisation in vitro [21]. To investigate the requirement for this palindromic sequence in HIV-2 dimerisation in vivo, we mutated the first four bases of pal but maintained the bases involved in stem $\mathrm{B}$ formation (Fig. 1A, SM2). In HIV-2, initiation of dimerisation has been postulated to occur at the DIS, a palindrome located at the top of SL-1 (Fig. 1B) [21,22]. Interestingly, mutations of the HIV-1 DIS revealed that the sequence was not required for genomic RNA dimerisation in vivo or for viral replication in primary cells but was important for replication in T cells $[25,26]$. Hence, we decided to examine whether the HIV-2 DIS was required for genomic RNA dimerisation and viral replication by mutating the first three bases of the palindrome (Fig. 1A, SM1).

None of the above described mutations had a significant effect on protein production by the virus as judged by western blot analysis (data not shown, [8]), even though the reverse transcriptase (RT) activities of the DM and SM2 mutants were slightly reduced compared to that of the wild type and SM1 mutant (data not shown), suggesting that the virus production is slightly lower for the two Psi mutants.

\section{Mutations of the HIV-2 packaging signal, but not the DIS, reduce genomic dimerisation in vivo}

We analysed the effect of the mutations in the packaging signal (DM and SM2) and the DIS (SM1) on genomic RNA dimerisation. Virion RNA extracted from wild type and mutant HIV-2 was analysed by non-denaturing northern blot (Fig. 2A) and the percentage of dimer present in each sample was quantified by densitometry (Fig. 2B). RT activity was measured to load RNA from an equivalent amount of virus particles in each lane. Wild type HIV-2 RNA appeared mostly dimeric within the virion $(80 \%$, Fig. 2B), whereas viruses bearing mutations in the Psi region (DM and SM2) showed a significant defect in dimerisation, with around 30 to $35 \%$ dimer (Fig. 2B), in addition to a reduction in the apparent amount of RNA 
A.

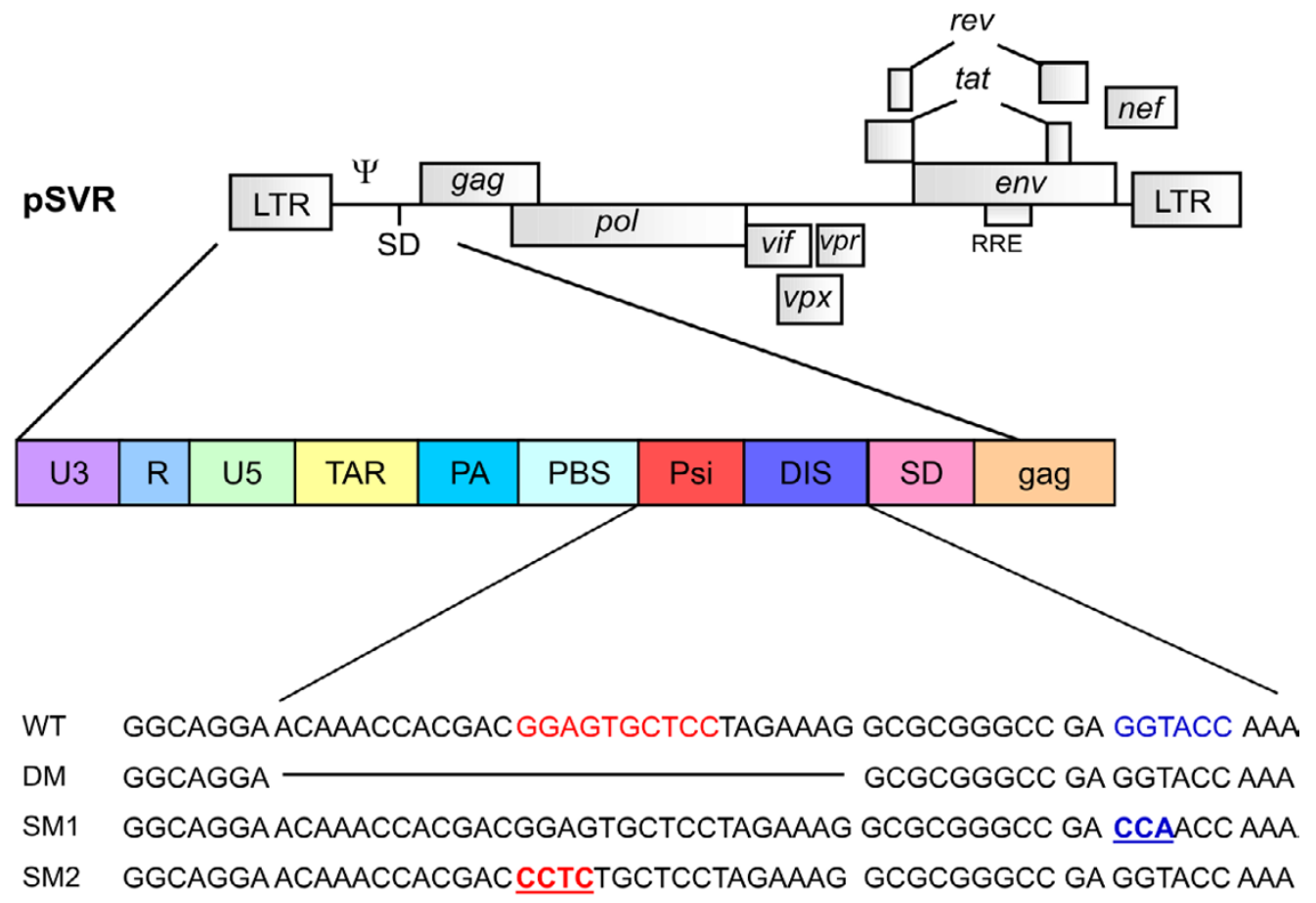

B.

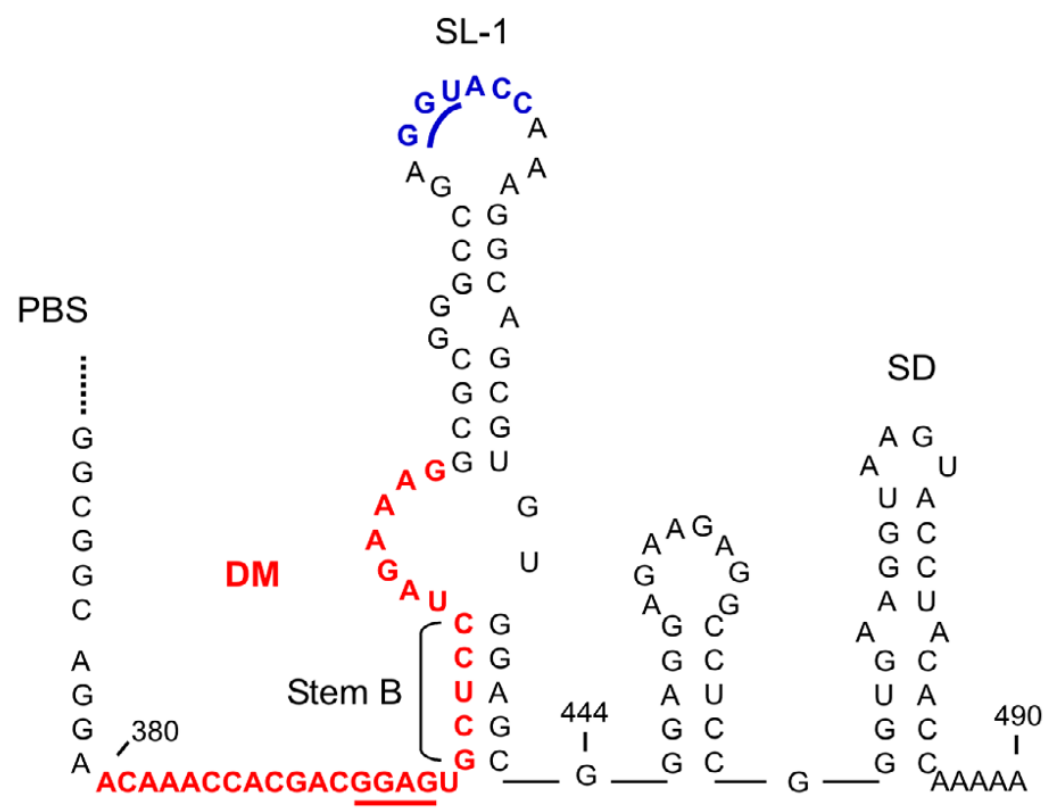

Figure I

Genomic and structural context of the mutations introduced in the HIV-2 leader. (A) Genomic organisation of HIV-2 and location of the mutations introduced. The DM deletion mutant has been described previously [8]. In SMI the first three bases in the DIS palindrome at position 420 of the HIV-2 RNA genome are substituted. In SM2 the first four bases of the Psi palindrome at position 392 of the HIV-2 RNA genome are substituted. (B) Structure of the SL-I region predicted by previously published biochemical analyses $[20,22,55,56]$ and mfold computer modelling $[57,58$. The position of the stem proposed to extend SL-I is indicated (stem B) [14]. 
A.

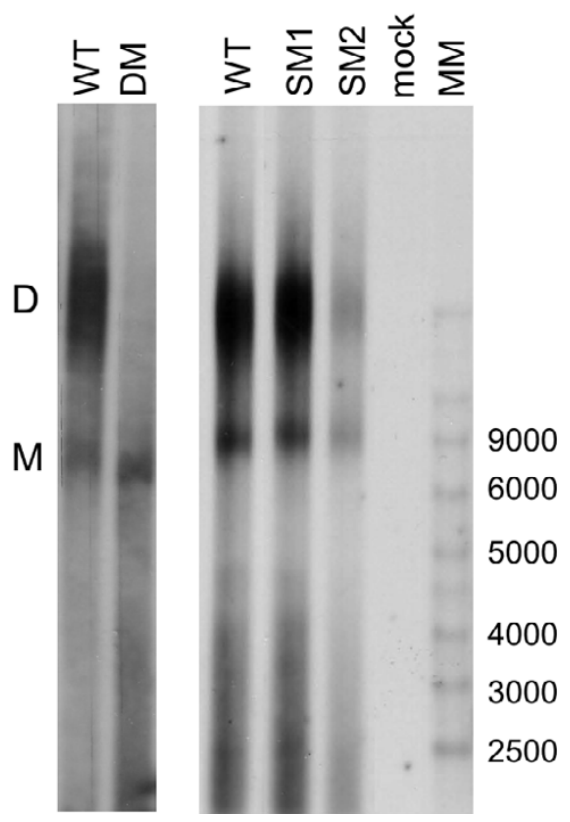

B.

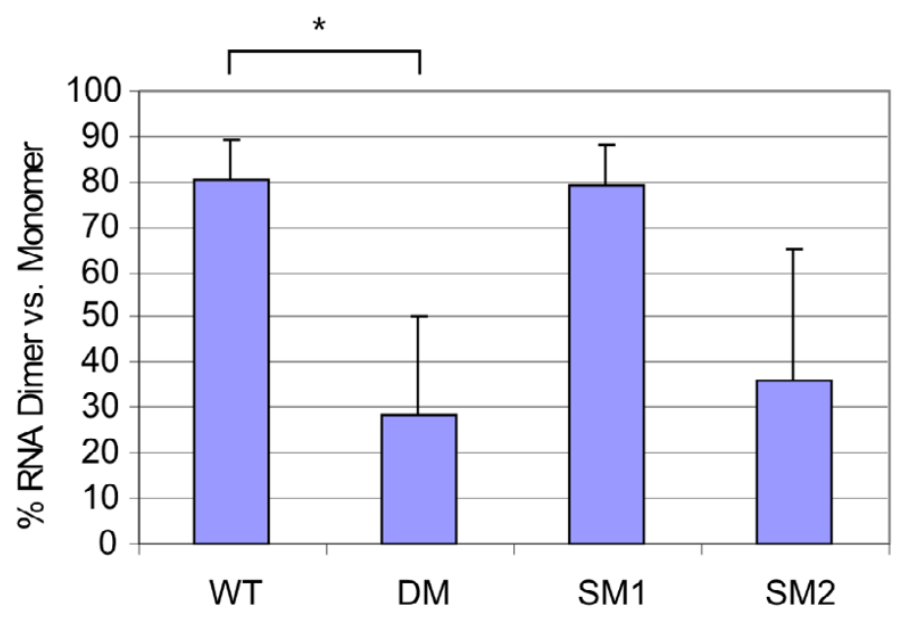

Figure 2

Mutations in HIV-2 packaging signal, but not in the DIS, render the RNA monomeric in vivo. (A) Native northern blot analysis of HIV-2 genomic RNA extracted from pelleted virions $48 \mathrm{~h}$ after COS-I cell transfection. RNA inputs were normalised on RT activity and an equivalent to $2.5 \times 10^{6} \mathrm{cpm}$ was used. WT, wild type; DM, Psi deletion mutant; SMI, DIS mutant; SM2, Psi pal mutant; mock, mock transfection; MM, Millennium RNA Markers (Ambion); M, monomer; D, dimer. (B) Bar chart representing the percentage of dimer present in each virion RNA sample. Data from at least three independent experiments are shown, error bars correspond to the SD. *, Student $t$ test $p$ value $<0.05$.

encapsidated (Fig. 2A). These results demonstrate that the Psi region contains a signal essential for efficient dimerisation in vivo and that at least part of it is mapped to the palindrome pal. Surprisingly, mutation of the DIS palindrome does not have an effect on dimerisation in vivo and $80 \%$ of the genomic RNA packaged appears dimeric (Fig. $2 \mathrm{~A}$ and $2 \mathrm{~B}$ ). This result contradicts data obtained in an in vitro dimerisation assay, where short RNA transcripts harbouring the SM1 mutation did not dimerise efficiently (data not shown). However, this discrepancy reflects the importance of working in the context of the whole virus, where different long-range interactions and secondary and tertiary structures than those observed in vitro $[10,12,27]$ might influence the ability of the genome to form a dimer. Furthermore, a number of factors such as the Gag and nucleocapsid (NC) proteins, which have been shown to promote dimerisation [10,27-30], are only present in the context of the virus.

\section{Encapsidation efficiencies of the HIV-2 mutants}

Deletion of the DM sequence (Fig. 1A) was previously reported to cause a severe packaging defect in HIV-2 [8]. Northern blot analysis of the SM2 mutant revealed a possible defect in encapsidation (Fig. 2A), even though only four bases of the Psi region are substituted in this mutant. To investigate this further, we assessed the level of HIV-2 genomic RNA in the cytoplasm of transfected cells and pelleted virions using RNase Protection Assay (RPA, Fig. 3 ). Wild type and mutant genomic RNAs were detected by probing with KS2 $\Psi$ KE (Fig. 3B) and the size of the protected fragments are shown in figure 3A. A specific riboprobe (KS2 $\Psi E P$ ) was used to measure plasmid DNA contamination (Fig. 3B). Finally, equal loading of cytoplasmic RNA was confirmed by probing for GAPDH mRNA (Fig. 3B). Packaging efficiencies, taken as the ratio of virion to cytoplasmic RNA of a mutant relative to the wild type, are reported in figure 3C. As observed in figure $2 \mathrm{~A}$, the SM2 mutant displayed some reduction in packaging (approx. 40\% on average). Although this figure is lower than for the DM deletion mutant, which showed a $70 \%$ decrease in RNA encapsidation, statistical analysis revealed that the difference in the packaging efficiencies of these two mutants was not significant. By contrast, the SM1 mutation of the DIS did not affect HIV-2 RNA encapsidation (Fig. 3C). 
A.

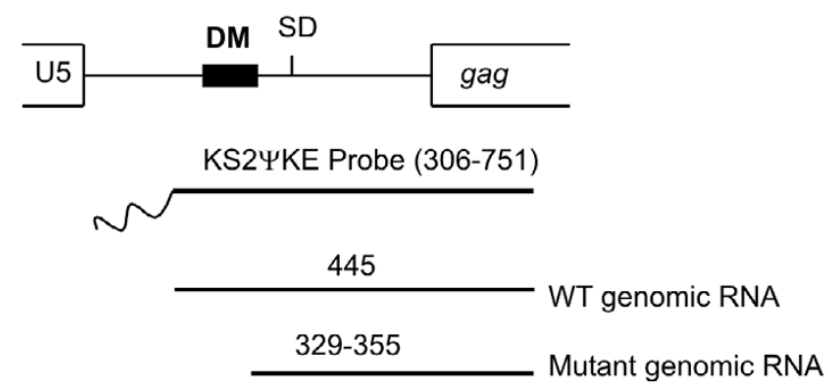

C.

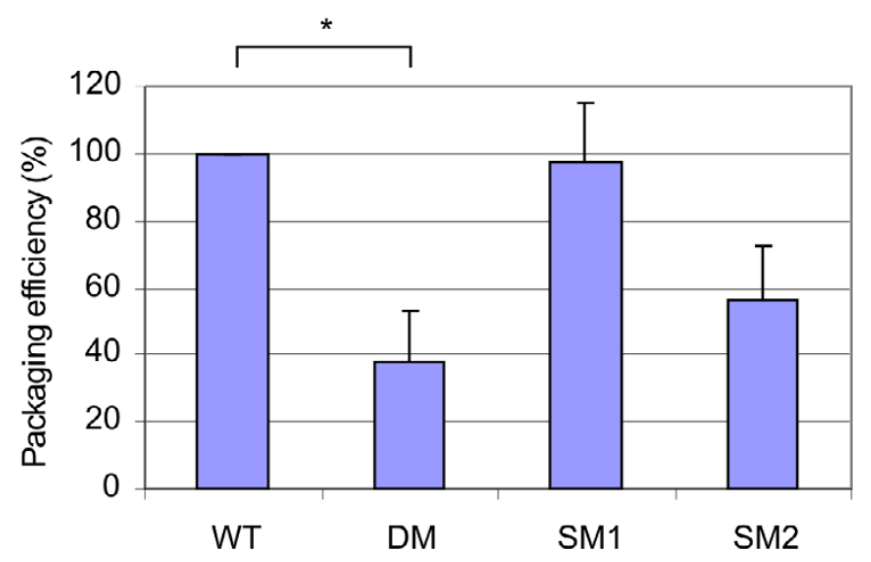

B.

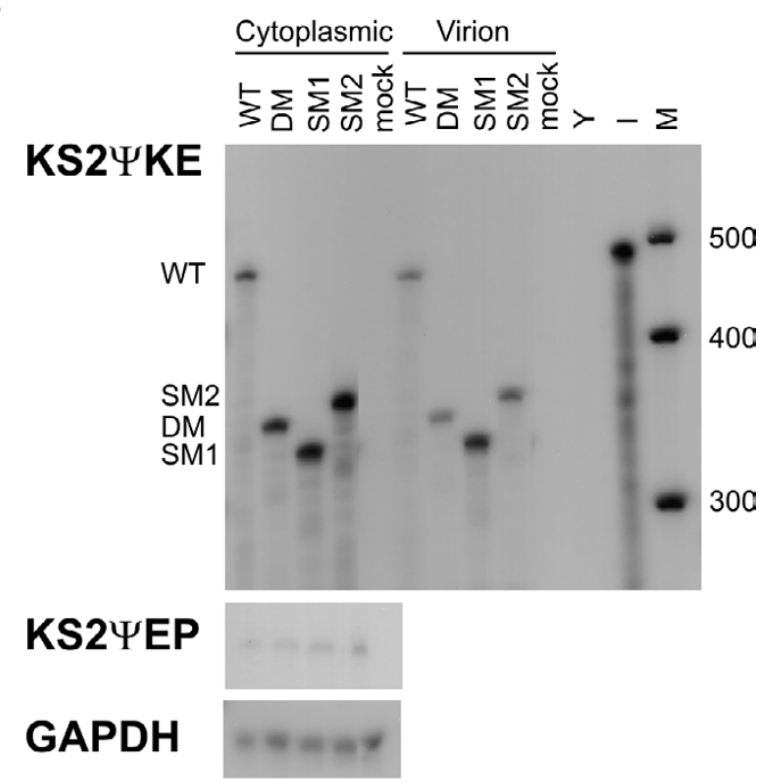

\section{Figure 3}

Encapsidation efficiency of the Psi and DIS HIV-2 mutants. (A) Size of the protected fragment corresponding to the viral genomic RNA when using the KS2YKE riboprobe in an RNAse protection assay (RPA). Protected mutant genomic RNAs vary in size between 329 and $355 \mathrm{nt}$ due to the position of the mutations. (B) Representative RPA where $2 \mu \mathrm{g}$ of cytoplasmic RNA and an equivalent of $2.5 \times 10^{6} \mathrm{cpm}$ of virion RNA was probed with I $\times 10^{5} \mathrm{cpm}$ of KS2 $Y K E$ riboprobe. Samples were also probed with I $\times 10^{5} \mathrm{cpm}$ of KS2 $\mathrm{WEP}$ and GAPDH riboprobes to detect plasmid DNA contamination and control for the loading, respectively. WT, wild type; DM, Psi deletion mutant; SMI, DIS mutant; SM2, pal mutant; mock, mock transfection; Y, yeast RNA + RNase; I, yeast RNA - RNAse (diluted I:I0); M, Century Plus RNA Markers (Ambion). (C) Packaging efficiencies of mutant HIV-2 relative to WT virus. Data from 3 independent experiments are shown, error bars correspond to the SD. *, Student $t$ test $p$ value $<0.005$

\section{Viruses with mutations in the packaging signal and} impaired dimerisation fail to replicate in T cells

Since the SM2 mutant exhibited a comparable reduction in the level of dimer as the DM mutant, but retained a greater portion of the HIV-2 packaging determinant and possibly encapsidated its genome more efficiently than the DM mutant, it was of interest to compare the replication kinetics of these two mutants (Fig. 4). Despite having no defect in RNA encapsidation or dimerisation, the SM1 mutant was included to verify that mutation of the DIS does not impair viral replication over a longer period of time. As shown on figure 4 , viral spread in the DM and
SM2 mutants was markedly reduced and the mutant viruses were not able to revert to a replication competent phenotype despite prolonged culture. The similar behaviour of the DM and the SM2 mutants suggest that a failure to encapsidate a dimeric genome rather than just a reduction in encapsidation might be responsible for the replication defect observed. Indeed, viral RNA dimerisation has been associated with viral infectivity in other retroviruses $[16,19,31,32]$. The SM1 mutant virus replicated as efficiently as wild type virus, confirming that an intact DIS palindrome is dispensable for the establishment of a productive infection. 


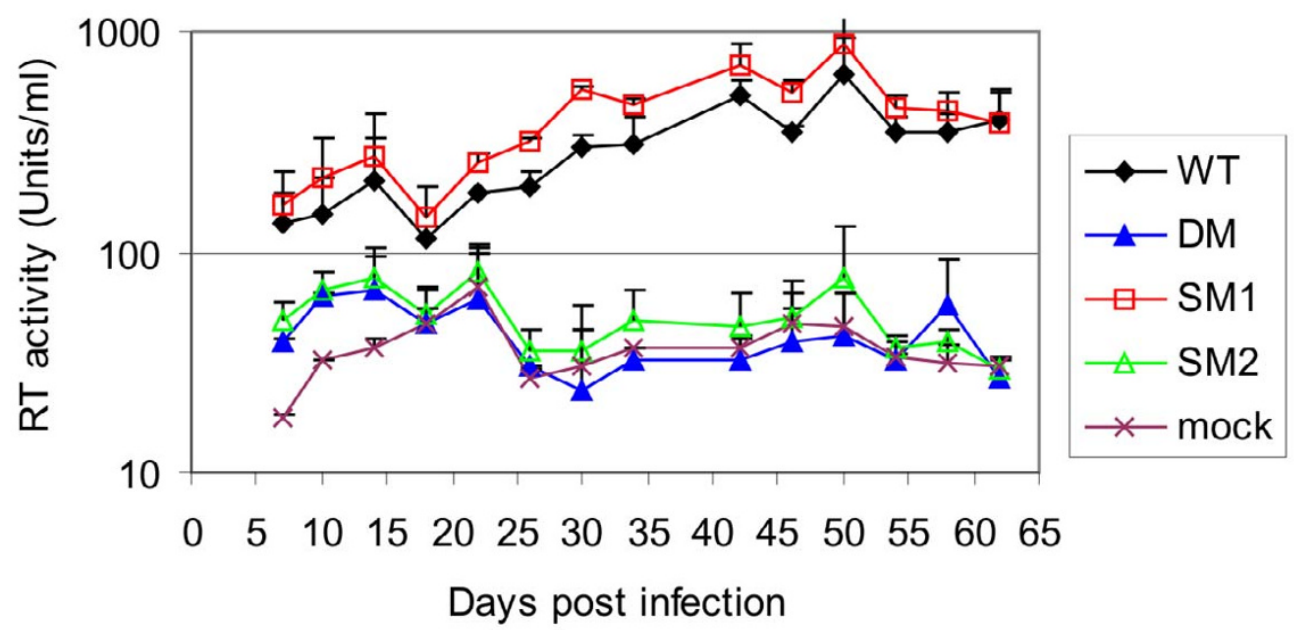

\section{Figure 4}

Mutations in the HIV-2 packaging signal affect replication of HIV-2 in T-cells. I $\times 10^{6}$ Jurkat T-cells were infected with an amount of virus equivalent to $\mathrm{I} \times 10^{7} \mathrm{cpm}$ as measured by RT activity assay. Replication was assessed by measure of the RT activity every 4 days. Cells were passaged I/2 every 8 days but no new cells or viruses were added at any point during the course of the infection. Data from two independent experiments are shown. Error bars represent the SD.

\section{Dimerisation deficient viruses display a reduced infectivity disproportionate to the packaging defect}

Although we now had evidence that mutation of the DM region, including pal, altered both genomic RNA encapsidation and dimerisation, it was important to know whether this alone was responsible for the very poor replication of the DM and SM2 viruses in T cells. Hence, we examined whether the mutant viruses were impaired in infectivity using the Ghost CCR5/CXCR4 reporter cell line which contains a stably transfected reporter cassette, consisting of an HIV-2 LTR driving expression of a green fluorescent protein ( $g f p$ ) gene. Successful infection of these cells by HIV-2 leads to activation of the cassette by the newly synthesised Tat protein and can be detected by measuring GFP production in the infected cells. We compared the infectivity of VSV-G pseudotyped wild type and mutant virions. Both the DM and the SM2 mutants showed a strikingly lower level of infectivity when equivalent amounts of virus, as measured by RT activity, were used to infect the Ghost cells (Fig. 5A). As observed in T cells, the SM1 mutation had no effect on the ability of the virus to infect permissive target cells. The envelopedeleted viruses or VSV-G envelope had no effect on GFP expression when the corresponding plasmids were transfected individually into COS-1 cells (data not shown). The VSV-G envelope was used to pseudotype envelopedeleted HIV-2. This may influence the ability of the virus to enter and hence infect the target cells because of the postulated difference in entry mechanism using this envelope. However, a preliminary experiment was carried out using full-length wild type and DM mutant HIV-2. Hela cells stably transfected with a reporter cassette, consisting of an HIV-1 LTR driving expression of a beta-galactosidase gene, were used. Similar results as those observed in the Ghost CCR5/CXCR4 cells were obtained (data not shown), even though the high level of background staining rendered the determination of an exact infectious titre difficult.

The reduced infectivity observed could be due to the defective packaging of the DM and SM2 viruses and thus the delivery of fewer genomes to the Ghost cells. Therefore, we were concerned to ensure that the absolute quantity of genomic RNA delivered to the Ghost cells was similar for wild type and mutant viruses. Since we have shown that the DM deletion virus displayed a three fold reduction in RNA encapsidation (Fig. 3C), we augmented the DM virus input by three fold so that a comparable number of genomes would be delivered to the Ghost cells (Fig. 5B). We verified the level of HIV-2 genomic RNA in two viral inputs by semi-quantitative RT-PCR performed on serial dilutions of the virus inoculum (Fig. 5B, top panel). To ensure that the RNA extraction process did not result in a loss of RNA, leading to differences in genomic RNA levels, a GAPDH carrier RNA was added prior to the extraction and analysed in parallel by RT-PCR as an internal control (data not shown). Interestingly, targeting equivalent numbers of HIV-2 genomes to the Ghost cells did not lead to equivalent infectivity (Fig. 5B). With both inputs tested, infectivity of the DM virus was three to five 
A.

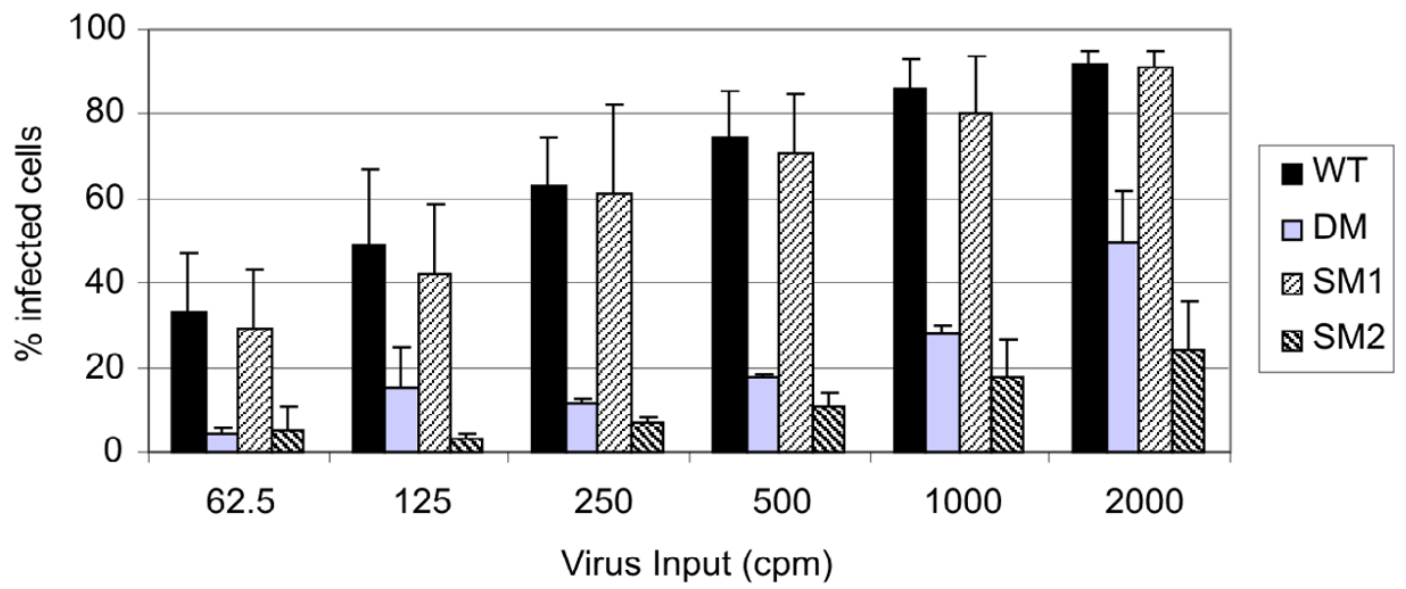

B.

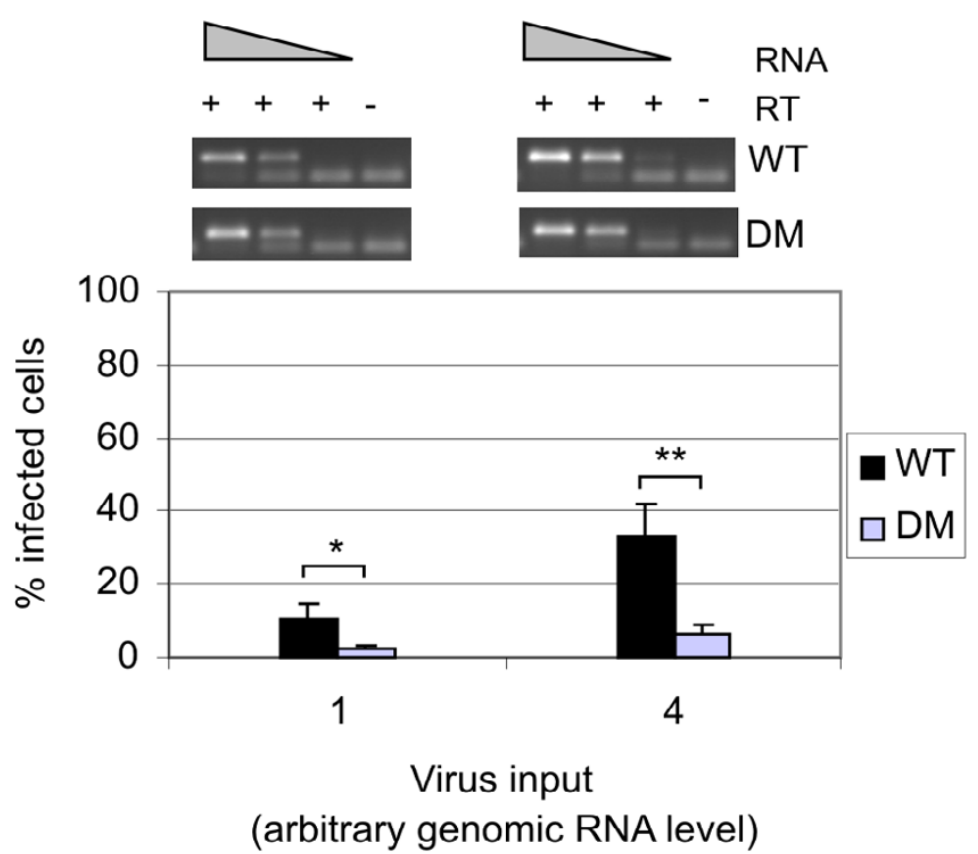

Figure 5

Virus infectivity is decreased by mutations in the Psi region. (A) Viral infectivity was determined using a reporter cell line expressing the gfp gene under the control of the HIV-2 LTR (Ghost CCR5/CXCR4). Equivalent amounts of VSV-G pseudotyped wild type (WT) and mutant HIV-2, normalised on RT activity, were used to infect $5 \times 10^{3}$ Ghost CCR5/CXCR4 cells and expression of GFP was measured at $72 \mathrm{~h}$ post-infection by FACS. Data from at least three independent experiments are plotted. Error bars represent the SD. (B) Virus inputs were adjusted according to the DM virus packaging defect as to infect the Ghost cells with an equivalent level of genomic RNA for WT and DM virus. Top panel: HIV-2 genomic RNA was extracted from two set amounts of virions used to infect the Ghost cells and viral RNA levels were assessed by semi-quantitative RTPCR using neat, I:I0 and I:I00 dilution of the RNA sample. A GAPDH carrier RNA was added during the extraction and amplified in parallel by RT-PCR to control for RNA loss during the RNA extraction (not shown). A control without RT was performed on $10 \mu$ of neat RNA (-). Bottom panel: The percentage of GFP positive cells was measured by FACS at $72 \mathrm{~h}$ postinfection. Arbitrary levels of RNA of I and 4 are equivalent to $62.5 \mathrm{cpm}$ and $250 \mathrm{cpm}$ of WT virus, respectively, as measured by RT activity assay. Data from four independent experiments are shown on the chart. Error bars represent the SD. *, Student t test $\mathrm{p}$ value $<0.05 ; * *$, $\mathrm{p}$ value $<0.01$. 
fold lower than that of the wild type virus. These results show that the infectivity defect seen in figure $5 \mathrm{~A}$ was not simply a consequence of reduced numbers of virus genomes entering the Ghost cells.

\section{Encapsidation of a dimeric genome is important for HIV-2 particle maturation}

To investigate whether there was any contribution of RNA encapsidation and genome dimerisation to viral assembly in HIV-2, we purified virions produced by cells transfected with either wild type or DM deletion provirus, both envelope-deleted, and analysed them using electron microscopy and negative staining. Electron micrographs were examined by two independent observers and approximately two hundred particles were identified for each virus. Representative particles containing immature, mature and multiple cores are shown in figure 6A (i), (ii) and (iii), respectively. We observed that cells transfected with the DM proviral DNA produced significantly fewer mature particles as compared to those transfected with wild type provirus (Fig. 6B). Surprisingly, the loss of mature particles for the DM virus was not accompanied by an increase in the proportion of immature virions (Fig. 6B). However, there was a larger number of duplex cores in the DM deletion virions, although this difference does not appear to be statistically significant (Fig. 6B). Furthermore, the existence of multiple cores in mature virions has been documented previously for the related virus HIV-1 [33]. These results show that a mutation in the HIV-2 packaging signal that also affects genome dimerisation leads to a reduction in the number of mature particles and an abnormal proportion of particles containing more than one core, possibly explaining the loss of infectivity associated with this mutation. Finally, it was also notable that the average diameter of the mutant virions was larger than that of the wild type virions (Fig. 6C). This did not appear to solely result from an increased number of particles containing multiple cores, unlike in HIV-1, where particles containing two cores were significantly larger than those containing a single core [33]. Taken together, these results suggest that genomic RNA encapsidation, genome dimerisation and virion particle morphology are extremely closely linked in HIV-2.

\section{Discussion}

We have explored the SL-1 region of the HIV-2 5' leader and shown that a signal essential for in vivo dimerisation in the viral particle is disrupted when the packaging signal is mutated. Substitution of four nucleotides in the Psi palindrome is sufficient to partially impair dimerisation and encapsidation of the virus, suggesting that the two processes may be linked. This result confirms a previous report showing that the Psi palindrome is involved in RNA dimerisation in HIV-2 [11,20].
Deletion of the whole Psi region significantly reduces the level of dimeric genome in the virions, in addition to causing a strong encapsidation defect.

While both Psi mutants exhibited a similar decrease in the percentage of dimer present (30\% and 35\% for DM and SM2, respectively), a large variation was observed. This reflects the difficulty of quantifying the dimeric RNA bands using densitometry. Indeed, the RNA dimer does not migrate as a distinctive neat band but rather as a variably spread band. In addition, it is not always possible to clearly distinguish the end of the dimer band from the beginning of the monomer band and the background in between. This is not a problem when analysing a virus that dimerises well, as the very strong intensity of the dimer band renders it easier to delimit and quantify (e.g. WT and SM1, Fig. 2A). Hence, even though the variation may appear quite large for the DM and the SM2 mutants, both viruses exhibited a significant reduction in the level of dimeric RNA packaged.

Similarly, although the defect in genomic RNA encapsidation observed for the DM mutant appears more pronounced than that observed for the SM2 mutant, both mutants encapsidated significantly less RNA than the wild type virus. Since only four bases were mutated in the SM2 virus as compared to a deletion of $28 \mathrm{nt}$ in the DM virus, it might explain the difference in the packaging efficiencies of DM and SM2. Furthermore, the stability of the genomic RNA dimer of the DM and SM2 mutant may not be the same and could influence the ability of these viruses to encapsidate their genomes. Further work in our laboratory will aim to determine if the different mutations introduced in the 5' UTR of HIV-2 affect the stability of the RNA dimer. This will help establish whether the same mechanism is involved in the reduction of viral infectivity observed with the DM and SM2 mutants.

The RNA dimer was shown to undergo protease-dependent maturation in Murine leukaemia virus (MuLV) and HIV-1 [30,34], although it was later demonstrated that Gag cleavage alone was not sufficient to promote dimer maturation [35]. The proteolytic processing of the p2/CA cleavage site and the spacer peptide $\mathrm{p} 1$ have both been implicated in the stability and maturation of the HIV-1 RNA dimer [36,37]. To date, it remains unclear as to whether the reduction in the level of dimer detected in the DM and SM2 mutant virions results from a defect in the dimer formation or a decrease of the dimer stability.

A recent study of HIV-1 dimerisation proposed that genomic RNA is packaged as a monomer and that dimerisation subsequently occurs at the DIS in a three-step protease-dependent mechanism [38], although several other studies in HIV-1 and MuLV suggested that dimerisation 
A.

(i)
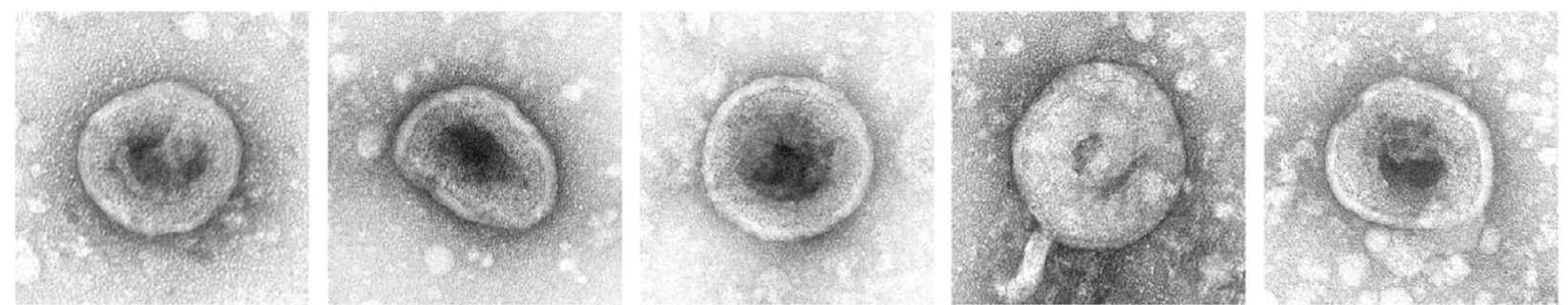

(ii)
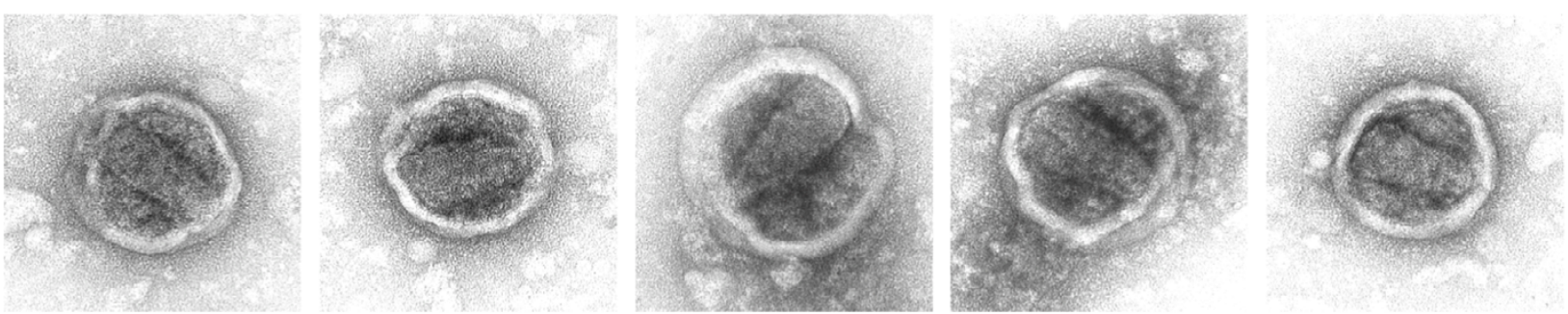

(iii)
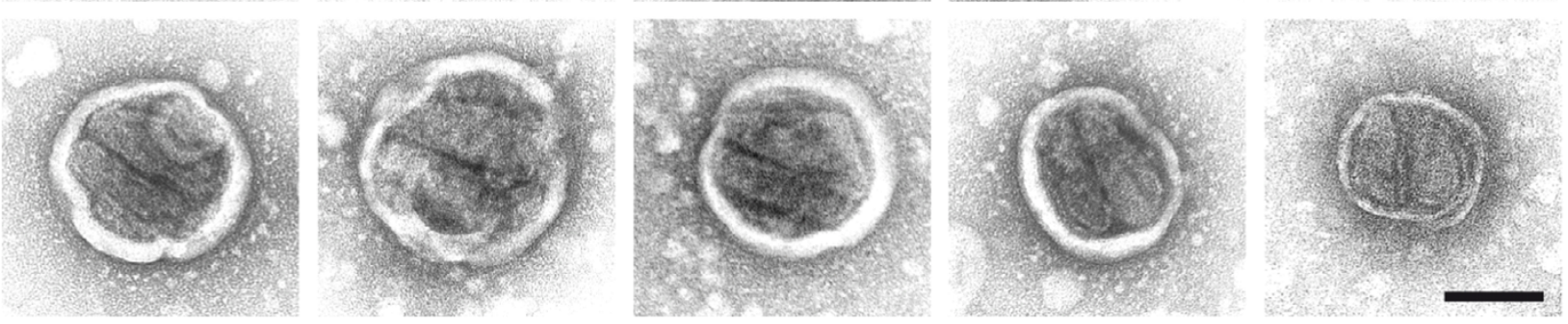

B.

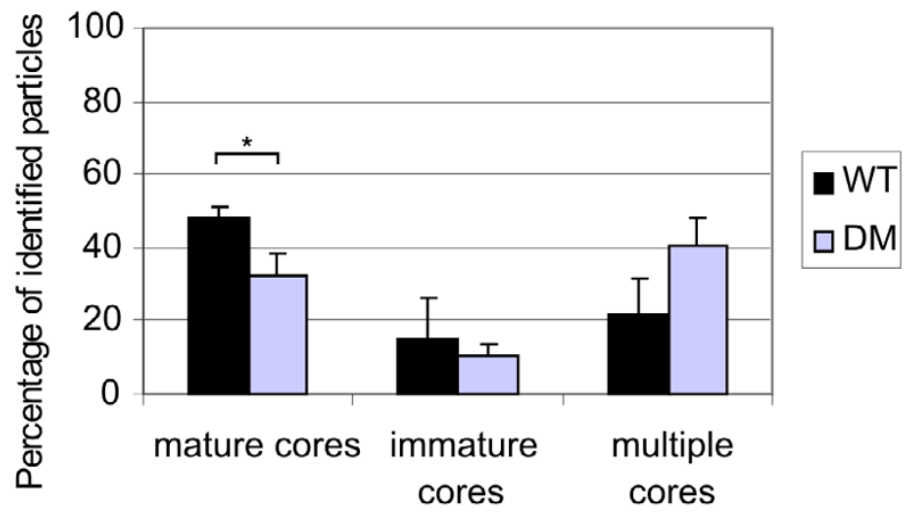

C.

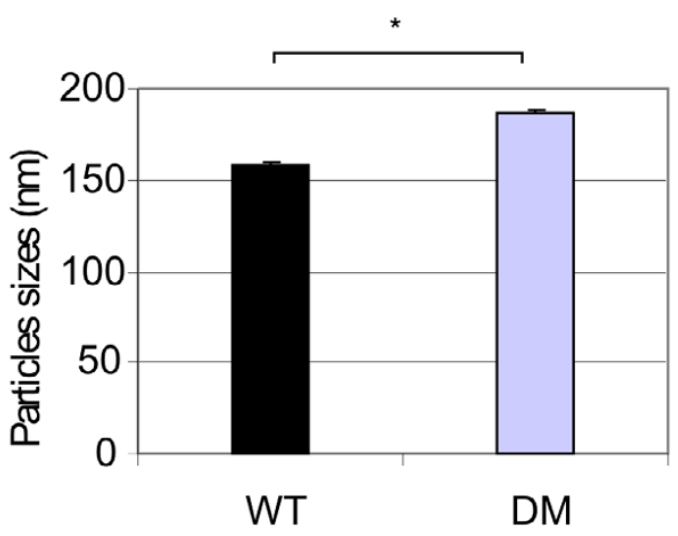

\section{Figure 6}

Efficient dimerisation and encapsidation are associated with correct assembly and particle maturation in HIV2. COS-I cells were transfected with envelope-deleted provirus and virions were harvested $48 \mathrm{~h}$ later. Purified HIV-2 particles were analysed by negative staining and electron microscopy. (A) Five examples of what were assessed as immature particles (i), mature particles (ii) and particles containing multiple cores (iii) are shown. Scale bar: $100 \mathrm{~nm}$. (B) The proportion of mature, immature and multiple core particles was calculated for wild type (WT) and DM mutant HIV-2 after examination of 193 WT and 199 DM particles by two individuals independently. Error bars correspond to the SD. *, Student $t$ test $p$ value $<0.05$. (C) The particles were measured and the average sizes of WT and DM particles were reported on the graph. Error bars correspond to the SD; $n=215$ for WT and 189 for DM; *, Student $t$ test $p$ value $<0.05$. 
might have already occurred within the infected cell $[15,17,39,40]$. Therefore, it would of interest to analyse whether the formation of dimeric HIV-2 genomic RNA occurs prior to encapsidation or involves a proteasedependent step.

The DM mutant shows a defect in infectivity that is independent of the reduction in encapsidation, as targeting a similar amount of genome to the target cells does not restore infectivity. Furthermore, both viruses mutated in the Psi region were unable to establish a productive infection in T cells, suggesting that encapsidation of a dimeric genome might be required for viral infectivity in HIV-2. This involvement of SL-1 in RNA encapsidation and dimerisation has been reported for simian immunodeficiency virus macaque ( $\left.\operatorname{SIV}_{\mathrm{mac}}\right)$, where mutations in this region also resulted in a reduction in viral infectivity [19].

Interestingly, introduction of a mutation in the DIS palindrome so that it was no longer self-complementary did not yield any decrease in the level of dimeric genome in vivo. This result contradicts previous in vitro studies where an SL-1-mediated dimerisation $[21,22]$ was proposed to be regulated by several long-range interactions $[10,11,27]$. However, in the context of the virus, different interactions and conformational changes might occur and trans-acting factors such as the Gag protein have been shown to promote dimerisation in HIV-1 and MuLV $[28,29]$. Furthermore, in HIV-1, the DIS palindrome was also reported to be dispensable for dimerisation in vivo [25] and replication in primary cells [26]. However, an intact HIV-1 DIS was required for efficient RNA packaging and viral replication in T cells $[16,25,32]$, which we did not observe in HIV-2. This suggests that the palindrome termed the DIS in HIV-2 is not an important Dimer Initiation Site in vivo, even though it might be involved at some stage of the dimer formation.

In the mutants of the Psi region studied here, there was a correlation between an encapsidation and a dimerisation defect, indicating that the two processes may be closely linked, as previously proposed for HIV-1, HIV-2 and MuLV $[11,16,25,32,40]$. This suggests either that one is dependent on the other or that the same or closely adjacent sequences are responsible for both processes.

The dimeric RNA genome has been shown to have a number of different roles in several stages of the retroviral life cycle, such as recombination during reverse transcription $[39,41]$ and proviral DNA synthesis $[16,42,43]$. In addition, RNA was proposed to have a structural role in MuLV [44]. We have now shown that, in HIV-2, the absence of a dimeric genome is associated with a severe replication defect which is disproportionately large compared to the diminution in RNA encapsidation. Packaging of monomeric genomes occurs but is less efficient than that of dimeric ones. However, delivery of viruses containing monomeric genomes to target cells is characterised by a reduction in infectivity which cannot be restored simply by increasing the number of genomes delivered. Thus, it seems that a monomeric genome impairs virus viability.

Previous studies have shown that RNA capture influences viral assembly by both affecting the efficiency and contributing to normal capsid morphology $[1,19,44,45]$. In SIV, mutations in the SL-1 region that resulted in a reduction of encapsidation and dimerisation also led to aberrant particle morphology [19]. EM of our viruses containing monomeric genomes shows that there is a significant reduction in particle maturation compared to when the dimeric genome is present and that larger cores can be detected. However, the proportion of immature particles in the mutant virus sample is similar to that of the wild type virus preparation, indicating that the mutant viruses undergo at least some degree of maturation. Furthermore, protein processing of the DM mutant appeared normal when analysed at the same time point of $48 \mathrm{hrs}$ post-transfection that we used in this study [8]. Nonetheless, a delay in protein processing cannot be excluded as the analysis was only performed at a single time point. In HIV-1, mutations of the DIS were reported to cause a delay in the processing of the p2 peptide [46], which has been demonstrated to be involved in the sequential proteolytic processing of the Gag protein [47]. In addition, RNA was proposed to be required for the cleavage of the HIV-1 NCp15 precursor [48], suggesting that binding of the nucleocapsid protein to the RNA might play a role in virion maturation. With this in mind, it would be interesting to analyse the protein processing of the mutant virus at several time points and determine whether the processing of the Gag and Gag-Pol polyproteins is affected.

Intriguingly, there is an increased number of particles containing duplex cores in the DM deletion virions. This phenomenon has previously been observed in HIV-1, where approximately $30 \%$ of the particles contained two cores [33]. Since we have shown here that the DM virions contain predominantly monomeric RNA, it is tempting to speculate that these cores each contain a single monomeric genome, although proving this rigorously will be challenging.

Our work is consistent with dimeric RNA being involved in efficient packaging in HIV-2. In MuLV, recent structural studies have implied that dimerisation of the genomic RNA leads to exposure of a high affinity Gag binding site in vitro [15], suggesting that dimeric RNA is important for the Gag:RNA interaction. Therefore, it would be of great interest to analyse whether our mutations in the SL-1/Psi 
region affect the binding affinity of the Gag protein to the RNA.

It remains to be seen whether the encapsidation process in other Lentiviruses, and particularly HIV-1, is also dependent on formation of an RNA dimer prior to Gag capture. Molecules which interfere with this process might be exploited as antiviral agents and would be expected to have a high degree of selectivity for the virus, since RNA export is virus specific in animal cells and export of a dimeric species is, as far as we know, unique to retroviruses. Indeed, there is recent evidence that oligonucleotides targeting the dimer linkage of HIV-1 are effective antiviral agents in vitro [49].

\section{Conclusion}

In this study, we have shown that in HIV-2, the cis-acting packaging and dimerisation elements are closely linked and may be part of the same structural region of the 5' UTR. Surprisingly, the DIS does not mediate HIV-2 genomic RNA dimerisation in vivo and does not seem to play a significant role in viral replication or infectivity. Packaging a monomeric genome appears to adversely affect the production of infectious viral particles and the virions that are produced have an abnormal morphology. It therefore seems likely that the dimeric genome plays an important role in the virion, both from its coding potential but also as a structural element ensuring optimal virus assembly.

\section{Methods}

\section{Plasmid construction}

pSVR is an infectious proviral clone of HIV-2 ROD containing a simian virus 40 origin of replication [7]. Restriction sites and nucleotide numbering, where given, are relative to the first nucleotide of the viral RNA. Proviral construct pSVRDM containing a 28 nt deletion in the $5^{\prime}$ leader has been previously described [8]. Mutations in the $5^{\prime}$ leader were introduced by site-directed mutagenesis [50] into a subclone of HIV-2, pGRAXS [8], using primers 5' GGCGCGGGCCGACCAACCAAAGGCAGCGTGTGG 3' and its complement and 5' GGAACAAACCACGACCCTCTGCTCCTAGAAAGGCG 3 ' and its complement for SM1 and SM2, respectively. Sequences from the resulting subclones were introduced into the provirus by exchanging an AatII-XhoI fragment, generating proviral constructs pSVRSM1 and pSVRSM2. Proviral constructs pSVR $\triangle$ NB and pSVR $\triangle$ NBDM which contain a 550 nt deletion in the env gene (positions 6369 to 6927 ) have been previously described [8]. pSVR $\triangle N B S M 1$ and pSVR $\triangle N B S M 2$ were generated by replacing the AatII-XhoI region of pSVR $\triangle \mathrm{NB}$ with the same region of PSVRSM1 and PSVRSM2 respectively. pCMV-VSVG contains the vesicular stomatitis virus (VSV) G glycoprotein gene in the context of pCDNA3 (Invitrogen). All plasmids based on HIV-2 proviral sequences were grown in TOPF' 10 (Invitrogen) Escherichia coli at $30^{\circ} \mathrm{C}$ to avoid recombination. All other plasmids were grown in DH5 $\alpha$ E. coli under standard conditions.

Plasmids used as template for production of riboprobes were constructed as follows. Plasmids KS2 $\Psi$ KE and KS2 YEP have been previously described $[8,51]$. They contain HIV-2 sequences from positions 306 to 751 and (107) to 306 of pSVR, respectively, cloned into the polylinker of the pBluescript KSII(+) transcription vector (Stratagene). A glyceraldehyde-3-phosphate dehydrogenase (GAPDH) riboprobe template was created by reverse transcriptase (RT)-PCR amplification of the sequence from position 61 to 346 of human GAPDH using 5' GGTGAAGGTCGGAGTCAACG $3^{\prime}$ and $5^{\prime}$ AATTAACCCTCACTAAAGGACTCCACGACGTACTC 3' primers. Total cytoplasmic RNA extracted from Jurkat $\mathrm{T}$ cells served as template for the reaction. In vitro transcription of the linearised plasmids and PCR fragment using T3 RNA polymerase yielded antisense riboprobes for use in the northern blot and RNase protection assay (RPA).

\section{Cell culturing and transfection}

COS-1 simian epithelioid cells, obtained from the European Collection of cell culture (ECACC), were maintained in Dulbecco's modified Eagle's medium (DMEM, Gibco BRL) supplemented with $10 \%$ fetal calf serum and $1 \times$ penicillin/streptomycin (Invitrogen). Cells were transfected in $10 \mathrm{~cm}$-diameter dishes by the DEAE-dextran method [52] with a total of $5 \mu \mathrm{g}$ of DNA. Cells and supernatants were harvested $48 \mathrm{~h}$ later, and virus production was assessed with a RT assay [53]. CD4+ human osteosarcoma (HOS) cells stably transfected with CCR5, CXCR4 and the green fluorescent protein $(g f p)$ reporter gene under the control of HIV-2 LTR (designated Ghost CCR5/ CXCR4), provided by the Centralised Facility for AIDS Reagents, NIBSC, UK, were maintained in DMEM supplemented with $10 \%$ fetal calf serum, $1 \times$ penicillin/streptomycin (Invitrogen), $100 \mu \mathrm{g} / \mathrm{ml}$ hygromycin (Invitrogen), $500 \mu \mathrm{g} / \mathrm{ml}$ geneticin (Gibco BRL) and $1 \mu \mathrm{g} / \mathrm{ml}$ puromycin (Sigma) as previously described [54]. Jurkat T cells, provided by the Centralised Facility for AIDS Reagents, NIBSC, UK, were maintained in RPMI 1640 medium (Roswell Park Memorial Institute, Gibco BRL) supplemented with $10 \%$ fetal calf serum and $1 \times$ penicillin/streptomycin (Invitrogen).

\section{T-cell replication assay}

Replication assays were performed as described previously [8] with the following modifications. Pelleted virus from two individual transfections were resuspended in $500 \mu \mathrm{l}$ RPMI 1640 each and pooled. Subsequently, an amount of virus equivalent to $1 \times 10^{7} \mathrm{cpm}$ of RT activity was added to $1 \times 10^{6}$ Jurkat cells in the presence of $10 \mu \mathrm{g} / \mathrm{ml}$ DEAEdextran in one well of a 6-well culture plate. After $24 \mathrm{~h}$ at 
$37^{\circ} \mathrm{C}$, cells were transferred into a $25 \mathrm{~cm}^{2}$ flask containing $10 \mathrm{ml}$ of media and virus replication was followed by measuring RT activity every 4 days. Cells were split $1 / 2$ every 8 days.

\section{Transduction of HOS-CD4+ LTR-GFP cells}

Supernatants of COS- 1 cells transfected with $5 \mu$ g envelope-deleted provirus and $5 \mu \mathrm{g}$ VSV-G expressor plasmid, $10 \mu \mathrm{g}$ envelope-deleted provirus alone or $10 \mu \mathrm{g}$ VSV-G expressor alone as well as mock transfected cells were harvested as previously described [8] except that pelleted virus from two individual transfections were resuspended in $500 \mu \mathrm{l}$ DMEM each and pooled. The RT activity of the resulting virus preparation was determined as described above and the amount of virus added to a 6-well plate of cells was normalised this way. Ghost CCR5/CXCR4 cells were seeded at $2 \times 10^{5}$ cells per well in selection medium $24 \mathrm{~h}$ prior to infection. Cells were exposed to increasing amount of WT and mutant viruses in the presence of $8 \mu \mathrm{g} /$ $\mathrm{ml}$ polybrene (Sigma) for $16 \mathrm{~h}$, after which the virus-containing medium was replaced by fresh selection medium. At $72 \mathrm{~h}$ post-infection, cells were washed twice with cold PBS, trypsinised and fixed in 2\% paraformaldehyde. GFP expression was measured by FACS analysis.

\section{RT-PCR}

Viral RNA from normalised amounts of virions was isolated using the QiAamp viral RNA kit (Qiagen). $1 \mu \mathrm{g}$ of in vitro synthesised GAPDH RNA (pos. 61 to 346) was added to each sample prior to extraction. The extracted RNA was treated with $5 \mathrm{U}$ TURBO DNase (Ambion) for $1 \mathrm{~h}$ at $37^{\circ} \mathrm{C}$, followed by heat inactivation for $10 \mathrm{~min}$ at $65^{\circ} \mathrm{C} .10 \mu \mathrm{l}$ of neat RNA, $1: 10$ or $1: 100$ dilution were used for RT-PCR using One step RT-PCR kit (Abgene) with HIV-2 Psi F 5' TAATACGACTCACTATAGGCTGAGTGAAGGC $3^{\prime}$ and Psi R 5' AGGTACTTACCTTCACCC 3'. A control without RT was performed with $10 \mu \mathrm{l}$ of neat RNA. Samples were visualised on a $2 \%$ agarose gel.

\section{RNA isolation}

Cytoplasmic and virion RNAs were harvested with the RNAeasy mini kit (Qiagen) and the QIAamp viral RNA kit (Qiagen), respectively. The isolated RNA was treated with $5 \mathrm{U}$ of TURBO DNase (Ambion) for $30 \mathrm{~min}$ at $37^{\circ} \mathrm{C}$ and extracted once with acid-buffered phenol-chloroform and once with chloroform. RNA was precipitated with ammonium acetate and ethanol and stored at $-80^{\circ} \mathrm{C}$.

\section{Northern blot analysis}

KS2 YKE biotinylated riboprobe was synthesised by in vitro transcription of linearised plasmid using T3 RNA polymerase (Promega), and purified with a G-50 column (Roche) prior to use in northern blot assays. Reagents for the northern blots were obtained from a commercially available kit (Ambion). Virion RNA input was normalised on RT activity, with an equivalent of $2.5 \times 10^{6} \mathrm{cpm}$ being the standard amount used per reaction. RNAs were subjected to non-denaturing electrophoresis on $0.8 \%$ LE-agarose (Ambion) gel. For size determination, biotinylated RNA Millennium markers (Ambion) were run in parallel. RNAs were transferred onto positively charged nylon membranes (Ambion) prior to incubation with $0.4 \mathrm{nM}$ riboprobe for $16 \mathrm{~h}$ at $68^{\circ} \mathrm{C}$. Detection was performed using the BrightStar Biodetect kit (Ambion). RNA was quantified by densitometry using the ImageJ software.

\section{RNase protection assays}

$\left[\alpha-{ }^{32} \mathrm{P}\right]$-labelled KS2 YKE riboprobe was synthesized by in vitro transcription of linearised plasmid using T3 RNA polymerase (Promega) and gel purified prior to use in RPA, as described previously [8]. RNA inputs were normalised on concentration, for cytoplasmic RNA, and RT activity, for virion RNA. Typically, $2 \mu \mathrm{g}$ of cytoplasmic RNA and an equivalent of $2.5 \times 10^{6} \mathrm{cpm}$ of viral RNA were used. For each experiment, a separate RPA was performed using the same RNA inputs but probing for viral plasmid DNA using a probe generated from plasmid KS2 YEP. In addition, a probe for human GAPDH RNA was included in the reaction to control for variations in cytoplasmic RNA input. Any DNA contamination or variations in the GAPDH signal were accounted for when calculating encapsidation efficiencies, taken as the ratio of virion to cytoplasmic RNA of a mutant relative to the wild type.

\section{Electron microscopy}

Supernatants of COS-1 cells transfected with envelopedeleted WT and DM deletion mutant proviruses were harvested as previously described [8]. Pelleted virions were resuspended in $10 \mu \mathrm{l}$ of $100 \mathrm{mM} \mathrm{NaCl}, 50 \mathrm{mM}$ MOPS buffer at $4{ }^{\circ} \mathrm{C}$ for $24 \mathrm{~h}$ prior to negative staining. $0.8 \mu \mathrm{l}$ of virion preparation was applied to a carbon coated grid and stained with a few drops of $1 \%$ uranyl acetate. Micrographs were recorded on a Philips EM208S at a nominal magnification of $\times 20,000$.

\section{Competing interests}

The author(s) declare that they have no competing interests.

\section{Authors' contributions}

$\mathrm{AL}$, JSG and AML designed the study. AL carried out the experiments. RAC performed the EM experiment. AL, JSG and AML drafted the manuscript. All authors read and approved the final manuscript.

\section{Acknowledgements}

The Ghost indicator cells, provided by Drs Littman and KewalRamni and the Jurkat cells, provided by the American Type Culture Collection (ATCC), were obtained from the NIBSC Centralised Facility for AIDS Reagents supported by EU Programme EVA (contract QLKZ-CT-1999-00609) and the UK Medical Research Council. This work was supported by the UK 
Medical Research Council (Award Number G9805564) and the Charles and Elsie Sykes Trust.

\section{References}

I. Aldovini A, Young RA: Mutations of RNA and protein sequences involved in human immunodeficiency virus type I packaging result in production of noninfectious virus. J Virol 1990, 64(5): 1920-1926.

2. Gorelick RJ, Nigida SM Jr., Bess JW Jr., Arthur LO, Henderson LE, Rein A: Noninfectious human immunodeficiency virus type I mutants deficient in genomic RNA. J Virol 1990, 64(7):3207-32II.

3. Harrison GP, Lever AM: The human immunodeficiency virus type I packaging signal and major splice donor region have a conserved stable secondary structure. J Virol 1992, 66(7):4|44-4I53.

4. Luban J, Goff SP: Mutational analysis of cis-acting packaging signals in human immunodeficiency virus type I RNA. J Virol 1994, 68(6):3784-3793.

5. Berkowitz RD, Ohagen A, Hoglund S, Goff SP: Retroviral nucleocapsid domains mediate the specific recognition of genomic viral RNAs by chimeric Gag polyproteins during RNA packaging in vivo. J Virol 1995, 69(10):6445-6456.

6. Dannull J, Surovoy A, Jung G, Moelling K: Specific binding of HIVI nucleocapsid protein to PSI RNA in vitro requires $\mathbf{N}$-terminal zinc finger and flanking basic amino acid residues. $E M B O$ J 1994, I3(7): I525-1533.

7. McCann EM, Lever AM: Location of cis-acting signals important for RNA encapsidation in the leader sequence of human immunodeficiency virus type 2. J Virol I997, 7 I(5):4 I33-4 I37.

8. Griffin SD, Allen JF, Lever AM: The major human immunodeficiency virus type 2 (HIV-2) packaging signal is present on all HIV-2 RNA species: cotranslational RNA encapsidation and limitation of Gag protein confer specificity. J Virol 200I, 75(24): I 2058-I2069.

9. Kaye JF, Lever AM: Human immunodeficiency virus types I and 2 differ in the predominant mechanism used for selection of genomic RNA for encapsidation. J Virol 1999, 73(4):3023-3031.

10. Dirac AM, Huthoff H, Kjems J, Berkhout B: Regulated HIV-2 RNA dimerization by means of alternative RNA conformations. Nucleic Acids Res 2002, 30( I 2):2647-2655.

II. Lanchy JM, Ivanovitch JD, Lodmell JS: A structural linkage between the dimerization and encapsidation signals in HIV2 leader RNA. RNA 2003, 9(8): 1007-1018.

12. Huthoff $H$, Berkhout $B$ : Two alternating structures of the HIVI leader RNA. RNA 2001, 7(I): |43-157.

13. Paillart JC, Skripkin E, Ehresmann B, Ehresmann C, Marquet R: In vitro evidence for a long range pseudoknot in the 5 '-untranslated and matrix coding regions of HIV-I genomic RNA. J Biol Chem 2002, 277(8):5995-6004.

14. Lanchy JM, Lodmell JS: An extended stem-loop I is necessary for human immunodeficiency virus type 2 replication and affects genomic RNA encapsidation. J Virol 2007, 8 I (7):3285-3292.

15. D'Souza V, Summers MF: Structural basis for packaging the dimeric genome of Moloney murine leukaemia virus. Nature 2004, 43 I(7008):586-590.

16. Paillart JC, Berthoux L, Ottmann M, Darlix JL, Marquet R, Ehresmann $B$, Ehresmann C: A dual role of the putative RNA dimerization initiation site of human immunodeficiency virus type $I$ in genomic RNA packaging and proviral DNA synthesis. J Virol 1996, 70( I 2):8348-8354.

17. Russell RS, Liang C, Wainberg MA: Is HIV-I RNA dimerization a prerequisite for packaging? Yes, No, Probably? Retrovirology 2004, I(22):

18. Torrent C, Gabus C, Darlix JL: A small and efficient dimerization/packaging signal of rat VL30 RNA and its use in murine leukemia virus-VL30-derived vectors for gene transfer. J Virol 1994, 68(2):66 I-667.

19. Whitney JB, Wainberg MA: Impaired RNA incorporation and dimerization in live attenuated leader-variants of SIVmac239. Retrovirology 2006, 3:96.

20. Baig TT, Lanchy JM, Lodmell JS: HIV-2 RNA dimerization is regulated by intramolecular interactions in vitro. RNA 2007, |3(8): | 34|-|354.
21. Lanchy JM, Lodmell JS: Alternate usage of two dimerization initiation sites in HIV-2 viral RNA in vitro. J Mol Biol 2002, $319(3): 637-648$.

22. Dirac AM, Huthoff $\mathrm{H}, \mathrm{Kjems}$ J, Berkhout B: The dimer initiation site hairpin mediates dimerization of the human immunodeficiency virus, type 2 RNA genome. J Biol Chem 200I, 276(34):32345-32352.

23. Skripkin E, Paillart JC, Marquet R, Ehresmann B, Ehresmann C: Identification of the primary site of the human immunodeficiency virus type I RNA dimerization in vitro. Proc Natl Acad Sci U S A 1994, 9 I( I I):4945-4949.

24. Laughrea $M$, Jette $L$ : A I 9-nucleotide sequence upstream of the 5 ' major splice donor is part of the dimerization domain of human immunodeficiency virus I genomic RNA. Biochemistry 1994, 33(45): | 3464- | 3474.

25. Berkhout B, van Wamel JL: Role of the DIS hairpin in replication of human immunodeficiency virus type I. J Virol 1996, 70(10):6723-6732.

26. Hill MK, Shehu-Xhilaga M, Campbell SM, Poumbourios P, Crowe SM, Mak J: The dimer initiation sequence stem-loop of human immunodeficiency virus type $I$ is dispensable for viral replication in peripheral blood mononuclear cells. J Virol 2003, 77( I 5):8329-8335.

27. Lanchy JM, Rentz CA, Ivanovitch JD, Lodmell JS: Elements located upstream and downstream of the major splice donor site influence the ability of HIV-2 leader RNA to dimerize in vitro. Biochemistry 2003, 42(9):2634-2642.

28. Darlix JL, Gabus C, Nugeyre MT, Clavel F, Barre-Sinoussi F: Cis elements and trans-acting factors involved in the RNA dimerization of the human immunodeficiency virus HIV-I. J Mol Biol 1990, 2 I 6(3):689-699.

29. Prats AC, Roy C, Wang PA, Erard M, Housset V, Gabus C, Paoletti C, Darlix JL: Cis elements and trans-acting factors involved in dimer formation of murine leukemia virus RNA. J Virol 1990, 64(2):774-783.

30. Fu W, Rein A: Maturation of dimeric viral RNA of Moloney murine leukemia virus. J Virol 1993, 67(9):5443 -55449.

31. Clever JL, Parslow TG: Mutant human immunodeficiency virus type I genomes with defects in RNA dimerization or encapsidation. J Virol 1997, 7 I(5):3407-34 I4.

32. Laughrea M, Jette L, Mak J, Kleiman L, Liang C, Wainberg MA: Mutations in the kissing-loop hairpin of human immunodeficiency virus type I reduce viral infectivity as well as genomic RNA packaging and dimerization. J Virol 1997, 7 I(5):3397-3406.

33. Briggs JA, Wilk T, Welker R, Krausslich HG, Fuller SD: Structural organization of authentic, mature HIV-I virions and cores. EMBO J 2003, 22(7): I707-I715.

34. Fu W, Gorelick RJ, Rein A: Characterization of human immunodeficiency virus type I dimeric RNA from wild-type and protease-defective virions. J Virol 1994, 68(8):50 I3-5018.

35. Fu W, Dang Q, Nagashima K, Freed EO, Pathak VK, Hu WS: Effects of Gag mutation and processing on retroviral dimeric RNA maturation. J Virol 2006, 80(3): I242-1249.

36. Hill MK, Shehu-Xhilaga M, Crowe SM, Mak J: Proline residues within spacer peptide $\mathrm{pl}$ are important for human immunodeficiency virus type I infectivity, protein processing, and genomic RNA dimer stability. J Virol 2002, 76(22): I I 245-I I 253.

37. Shehu-Xhilaga M, Kraeusslich HG, Pettit S, Swanstrom R, Lee JY, Marshall JA, Crowe SM, Mak J: Proteolytic processing of the p2/ nucleocapsid cleavage site is critical for human immunodeficiency virus type I RNA dimer maturation. J Virol 200I, 75(19):9156-9164.

38. Song R, Kafaie J, Yang L, Laughrea M: HIV-I viral RNA is selected in the form of monomers that dimerize in a three-step protease-dependent process; the DIS of stem-loop I initiates viral RNA dimerization. J Mol Biol 2007, 37 I(4): I 084-I098.

39. Moore MD, Fu W, Nikolaitchik O, Chen J, Ptak RG, Hu WS: Dimer initiation signal of human immunodeficiency virus type I: its role in partner selection during RNA copackaging and its effects on recombination. J Virol 2007, 8 I (8):4002-40 II.

40. Hibbert CS, Mirro J, Rein A: mRNA molecules containing murine leukemia virus packaging signals are encapsidated as dimers. J Virol 2004, 78(20): 10927-10938.

41. Panganiban AT, Fiore D: Ordered interstrand and intrastrand DNA transfer during reverse transcription. Science 1988, 24 I (4869): 1064- 1069. 
42. Berkhout $B$, Das AT, van Wamel JL: The native structure of the human immunodeficiency virus type I RNA genome is required for the first strand transfer of reverse transcription. Virology 1998, 249(2):2| I-2|8.

43. Sakuragi J, Sakuragi S, Shioda T: Minimal region sufficient for genome dimerization in the human immunodeficiency virus type I virion and its potential roles in the early stages of viral replication. J Virol 2007, 8 I (I 5):7985-7992.

44. Muriaux D, Mirro J, Harvin D, Rein A: RNA is a structural element in retrovirus particles. Proc Natl Acad Sci U S A 200I, 98(9):5246-525।.

45. Clavel F, Orenstein JM: A mutant of human immunodeficiency virus with reduced RNA packaging and abnormal particle morphology. J Virol 1990, 64(I 0):5230-5234.

46. Liang C, Rong L, Cherry E, Kleiman L, Laughrea M, Wainberg MA: Deletion mutagenesis within the dimerization initiation site of human immunodeficiency virus type I results in delayed processing of the $\mathbf{p} 2$ peptide from precursor proteins. J Virol 1999, 73(7):6147-6151.

47. Pettit SC, Moody MD, Wehbie RS, Kaplan AH, Nantermet PV, Klein $C A$, Swanstrom R: The $\mathbf{p}$ domain of human immunodeficiency virus type I Gag regulates sequential proteolytic processing and is required to produce fully infectious virions. J Virol 1994 68(1 2):8017-8027.

48. Sheng $N$, Erickson-Viitanen $S$ : Cleavage of $\mathrm{p} / 5$ protein in vitro by human immunodeficiency virus type I protease is RNA dependent. J Virol 1994, 68(10):6207-62 I4.

49. Jakobsen MR, Haasnoot J, Wengel J, Berkhout B, Kjems J: Efficient inhibition of HIV-I expression by LNA modified antisense oligonucleotides and DNAzymes targeted to functionally selected binding sites. Retrovirology 2007, 4:29.

50. Kunkel TA, Roberts JD, Zakour RA: Rapid and efficient site-specific mutagenesis without phenotypic selection. Methods Enzymol 1987, I 54:367-382.

5I. Kaye JF, Lever AM: Nonreciprocal packaging of human immunodeficiency virus type I and type 2 RNA: a possible role for the p2 domain of Gag in RNA encapsidation. J Virol 1998 72(7):5877-5885.

52. Mortlock D, Keller EB, Ziegra CJ, Suter MM: High efficiency transfection of monkey COS-I cells. J Tissue Culture Methods 1993, 15:176-180.

53. Potts B): Mini RT assay. In Techniques in HIV research Edited by: Aldovini A, Walker BD. New York, Stockton Press; 1990:103-106.

54. Trkola A, Ketas T, Kewalramani VN, Endorf F, Binley JM, Katinger H, Robinson J, Littman DR, Moore JP: Neutralization sensitivity of human immunodeficiency virus type I primary isolates to antibodies and CD4-based reagents is independent of coreceptor usage. J Virol 1998, 72(3): 1876-|885.

55. Damgaard CK, Dyhr-Mikkelsen H, Kjems J: Mapping the RNA binding sites for human immunodeficiency virus type-I gag and NC proteins within the complete HIV-I and $\mathbf{- 2}$ untranslated leader regions. Nucleic Acids Res 1998, 26(16):3667-3676.

56. Lanchy JM, Szafran ON, Lodmell JS: Splicing affects presentation of RNA dimerization signals in HIV-2 in vitro. Nucleic Acids Res 2004, 32(I 5):4585-4595.

57. Zuker M: Mfold web server for nucleic acid folding and hybridization prediction. Nucleic Acids Res 2003, 3 I( I3):3406-34I5.

58. Mathews DH, Sabina J, Zuker M, Turner DH: Expanded sequence dependence of thermodynamic parameters improves prediction of RNA secondary structure. J Mol Biol 1999, 288(5):9| I-940.
Publish with Biomed Central and every scientist can read your work free of charge

"BioMed Central will be the most significant development for disseminating the results of biomedical research in our lifetime. "

Sir Paul Nurse, Cancer Research UK

Your research papers will be:

- available free of charge to the entire biomedical community

- peer reviewed and published immediately upon acceptance

- cited in PubMed and archived on PubMed Central

- yours - you keep the copyright

Submit your manuscript here:

http://www.biomedcentral.com/info/publishing_adv.asp
BioMedcentral 